\title{
Knowledge Systems: A Catalyst for Innovation and Organizational Learning Support in Decision-Making for Efficiency Improvement
}

\author{
Mohammed A, Ahmed AL-DUJAILI (Corresponding author) \\ School of mechanical, Aerospace and Civil Engineering, University of Manchester, \\ Manchester, M13 9PL, UK \\ Email: mhammedaldujaili@yahoo.co.uk
}

Accepted: July 30, 2011 DOI: 10.5296/ijhrs.v1i1.825

\begin{abstract}
All businesses have access to an extensive pool of knowledge, whether this is their understanding of customers' needs and the business environment or the skills and experience of employees. This has led to the use of different methodologies and strategies that are based on the type of evaluation required in the work. Accordingly, these research aims tie together the concept of knowledge management (KM), decision support system (DSS) and efficiency as a way of creation of continuable competitive advantage for the firms. A conceptual model is extracted from the literature review, developed and supported by knowledge experiences of senior workers. An initial study with consolidating firms that are effective in the industrial sector of the world was a lead to validating the study model and smoothing the progress of achieving investigation of the adopted relationships by the study. Collecting data was completed via interviews with managers and knowledge workers of the firms in addition to use of the survey questionnaire which was distributed to random samples from these firms. The research characterized a strong correlation between KM, DSS, and its types. Additionally, it characterized high correlation between DSS and efficiency. Therefore, the knowledge obtained in the current study could be updated for subsequent future steps in more development to the relationships among the same variables or other variables with KM.
\end{abstract}

Keywords: Knowledge Management System, Learning, Innovation, Sourcing Knowledge, Decision Support System, Efficiency. 


\section{Introduction}

Every year we get a chance to be acquainted with the companies' knowledge. We believe most in exemplifying the ideals of true knowledge management. This is the required adoption of practical insights and experiences, including the insights and experiences comprised in knowledge that were embodied in employees or embedded in organizational processes or practice through learning (LEA) and innovation developed. Accordingly, Alavi et al. (2001) said of this matter that some of the common applications of KMS are: (1) organizing and sharing/transferring of internal benchmarks/best practices, (2) constructing corporate knowledge directories, such as corporate yellow pages, people information archives, and (3) creating knowledge networks and knowledge maps. There are many others. This is the action that can create wealth of knowledge to the companies and achieve a competitive edge to them.

\section{Literature Review}

$\mathrm{KM}$ is nowadays the hottest topic. This is because knowledge is actually "a fluid mix of framed experience, values, contextual information, and expert insight that provides a framework for evaluating and incorporating new experience and information". It "originates and is applied in the minds of knowers" (Chryssolouris, G. et al., 2008). In other words, new knowledge acquisition is indispensable in the development and improvement of new skills in work. That is because ease of understanding and effectiveness in learning by employees are significant considerations for organizations in corporate knowledge acquisition (Andrew, 1998).

Furthermore, for many organizations, innovation is at present a required and fundamental element of the firms' sustainability in the marketplace. This is because it considers significant and complex dimensions of learning in work due to using a mix of rationale, the spontaneous processes affecting practising communities (Busch et al., 2006), whereas according to Liao et al. (2009) knowledge acquisition and creation are considered internally in the companies as the first steps in acquiring knowledge from the external environment to turn it into effective action that can be applied or used within organizations. Consequently the companies must work hard and quickly in disseminating knowledge practically in all of its districts to create innovation among employees.

Consequently, according to Beydoun et al. (1997) the firms move towards acquiring such knowledge in the course of a close interaction of an expert with a system performing the search on a tangible specific problem situation. This is because knowledge acquisition is broadly considered to be a painstaking modelling activity, when what is modelled is the expertise of a scope expert. This model has a go in order to be described in the knowledge level. Thereby, adoption of such models is trying to significantly advance the detailed conceptual analysis from the domain and the knowledge available.

Ultimately, according to Puranam (2001) it is believed that the organizational learning process during knowledge acquisition is considered as 'grafting', as its purpose is to acquire complex patterns of information or knowledge. This is because knowledge-grafting through 
imitation is faster from knowledge acquisition with experience, and therefore the firms are lunged towards a grafting of the new capabilities at the organizations' current knowledge base in order to develop the processes of the manufacturing.

\subsection{Organizational Learning}

All people are born with the ability to learn and they are thought to be learning if they adapt to the changing and evolving environment. Also, they are trying to learn leads for new insights and concepts, for the purpose of converting the information into relevant knowledge. This overwhelmingly occurs if they take effective actions and they detect and correct their own mistakes to achieve their aims (Argyris et al., 1978).

However, March (1991) stated that there are two types of organizational learning. Firstly, exploitative learning can occur when new behavioural capacities are framed within existing insights. Exploitative learning is described in the literature as a "single loop" that can be characterized as "first-order", "evolutional", "frame-taking", "reactive" and "incremental". Secondly, exploitative learning occurs when organizations acquire behavioural capacities that differ fundamentally from existing insights. Exploration is about discovery, variation, effectiveness, flexibility, and innovation.

Overall, organizational learning creates more through a process of acquiring, sharing, and integrating new knowledge that comes to the firm from outside as well as inside (Crossan et $a l ., 1999)$. Accordingly, exploration results in a relatively mighty and generalized search to expand the knowledge scope of companies in new or previously unprecedented areas in the companies and/or the establishing of new combinatory mechanisms. On the other hand, the exploitation may also rely on more narrow, localized, and in-depth search and/or repetitive combinatory mechanisms in order to obtain clear solutions relevant to a firm's existence and knowledge domains (Galunic et al., 1998; Katila et al., 2002 and McGrath, 2001). Figure 1 shows how knowledge management focuses on the creation or acquisition of knowledge by an organization during the learning (King, W.R., et al., 2008).

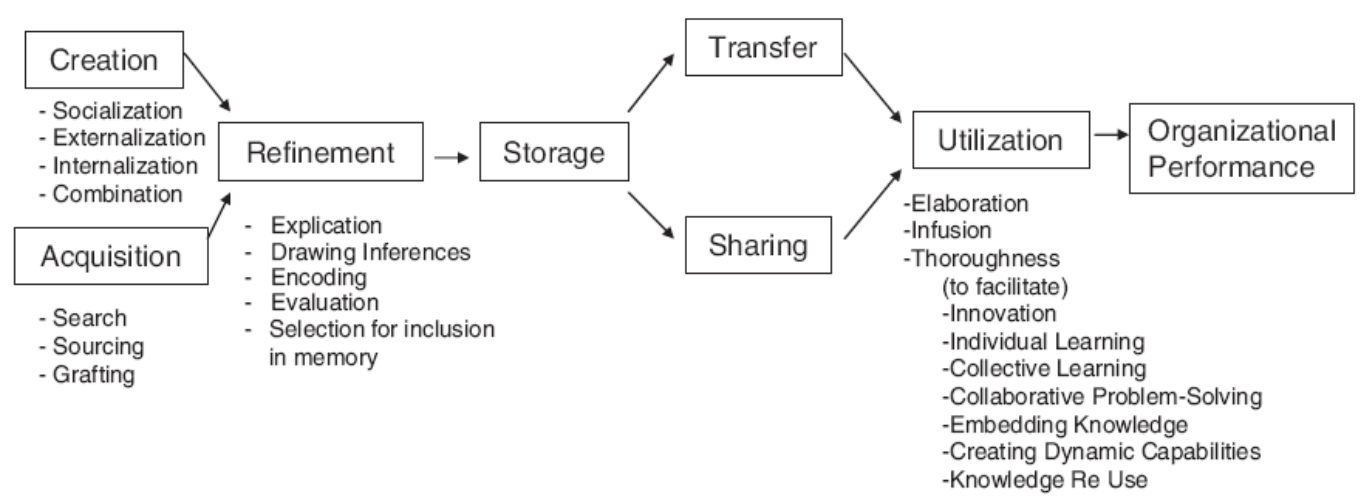

Figure 1: The Knowledge Management Cycle Model (King, W.R., et al, 2008).

Furthermore, a learning organization has the ability to adjust continuously to new situations 
and renew itself according to the demands of the environment (Jaw et al., 2003). Therefore, Tsang (1997) proposed that to enhance its capability to learn, an organization should establish a system whereby individual learning can be shared among members. Learning by the individual should be the basis of organizational learning (Grant, 1996).

\subsection{Knowledge Management and Innovation}

Knowledge and innovation (INN) play an increasingly imperative role in technological advances to the firms. This is because the innovation can come from internal units within the organizations (Auernhammer, K et al., 2003). In the same direction, the innovation also relies heavily on science and technology, because knowledge management tools are the basic technological building blocks of any specific knowledge management system. Individual tools can be combined or integrated to form a specific knowledge management system that performs particular functions such as knowledge storage and retrieval (Hughes, L. P. et al., 1998; Gallupe, 2000).

Accordingly, the innovation as illustrated above is knowledge development, and in particular, the implementation of knowledge or techniques to business or the manufacturing challenges, or the intersection between techniques and processes (Ho D., 2007). According to OECD (1997) the innovation has five elements: 1) The introduction of a new product or a qualitative change to an existing product. 2) The introduction of a process new to an industry. 3) The opening of a new market. 4) The development of new sources of supply for raw materials or other inputs. 5) Changes in industrial organization.

On the other hand, encouraging individuals to brainstorm can support the transfer of individual knowledge to organizational knowledge, meeting specific performance targets and increasing employee satisfaction, development and personal growth. This is because supporting the flow of information across the organization can help to inform newer employees and aid career development/progression (Draghici, A. et al., 2008; Spender, J., 1994; Gao, F. et al., 2008; Maier, R., 2003).

Ultimately, Gieskes, J. F. et al., (2002) consider the product innovation operation to be a sustainable and cross-functional operation that includes the sharing and transfer of knowledge within the many steps of the creativity operation, and the integration of a growing amount of differing efficiency inside and outside the organizational boundaries.

\subsection{Knowledge Management and Decision Support Systems}

In this stage knowledge moves from individual to collective and, on the contrary, from collective to individual. Therefore, at first the managers have a deep idea about the issue. Also they try to divide the problem into different portions or components. This is because the knowledge at this point is a conjectural and implicit one, but most commonly speaking, emotion. Emotion gives individuals the power to choose a solution in relation to a specific event (the context) and should be considered as the basis of intuition. This emotion is also an explication of improvisation.

Over and above that, at this stage of the decision-making process, it gives sense to some 
specific information or explicit knowledge that is not necessary related to the dominant logic (Prahalad, C. K. et al., 1986). Consequently, the organizations that do this have to capture and share knowledge that is found within the organization (Kiku, J., 2006).

This is because the implementation of DSS soaks up well the management ideas providing efficient methodology to the companies for the purpose of contribution in diagnosis and solution of the problems in the work, whereas the companies' knowledge management can benefit a lot more than DSS as follows (Sui, L., 2005). 1) Fast calculating - a computer allows the decision-maker to do a lot of calculations at high speed at low cost as well as make timely decisions, which is very critical to management in many cases. 2) Surpassing the human limit in processing and storing information - this is because humans are unable to memorize all information without mistakes at any time. 3) Cognition limit - this occurs when the companies need various kinds of knowledge and information, because individual ability to solve these problems will be restricted. In that case, more people together will be helpful. 4) Cutting down expense - it's costly to gather a group of decision-makers, especially a group of experts. By contrast, the computerized system support can cut the group size and allow the group members to communicate across different places (saving travelling expenses). 5) Information support - with the application of computer technology, the manager can get correct, timely, and latest information to make decisions. Data can be stored in different databases inside or outside the organization and with sound and pictures. Additionally, it can transmit the needed information quickly and economically. 6) Quality support - DSS can enhance the decision quality due to the ability of evaluating more alternate programs, and quickly making risk analysis and collecting experts' opinions at high speed and low cost (maybe these experts are in different places). Furthermore, it can get a lot of specialized knowledge that is drawn by the computer system, as well as with the capacity to carry out the complex simulation by decision-makers. This will result in better decisions. 7) Knowledge discovery and knowledge sharing - in this stage beginning building the firm's data repository and performing the data mining, data statistics, and data analysis based on it, the implicit knowledge about the firm can be found.

Therefore, the decision support system can realize an efficient, safe, and cooperated knowledge management and knowledge maintenance through the reasonable definition of the firm's business process and organization structure as well as the employee relationship. This means there is an access ease, and update, improvement, application and feedback of knowledge can be exercised through the excellent knowledge base management system designed, based on DSS. Figure 2 below is explaining a decision support system model based on knowledge management. 


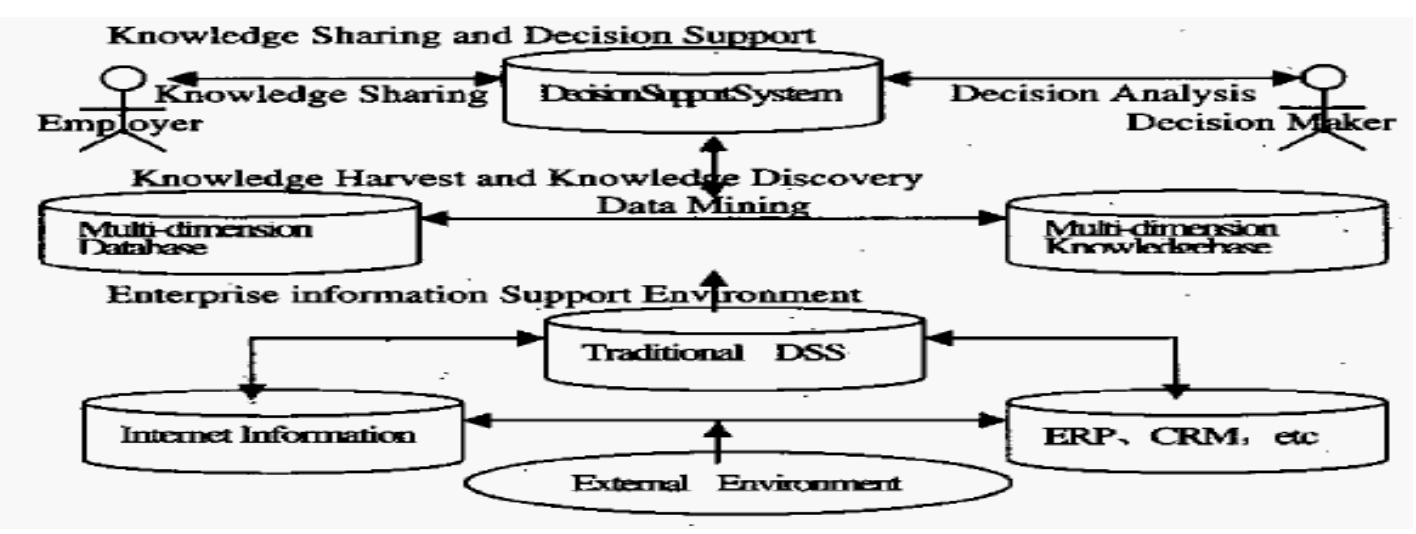

Figure 2: Decision Support System Model Based on Knowledge Management (Sui, 2005)

However, there are several kinds of DSS, as:

1) Group Decision Support Systems (GDSS). Parker et al. (1993) classified GDSS through the level of support provided to the members of the group, in this way: "The first level provides the technological DSSs that enable group members to communicate electronically with each other. On a second level: DSSs provide support for members of the group in the decision-making process. As well as the technological capacity which is provided with the first level, the second level is equipped to support joint models, analytical approaches and to support the determination of the preferences of the group through some kind of voting arrangement, rating or other means. Techniques such as the Delphi technique, brainstorming, and other creative approaches that are characteristics of the collective, can be supported through this level. The third level provides a GDSS with all the possibilities of the second level.

However, problems of coordination and communication within the group will result. And then computer Decision Support System will help people make a quick visit and process mass stored information. Besides, it's helpful to reduce the problems of coordination and communication among the group members (Sui, L. 2005).

2) Expert Systems (ES): Liebowitz, J. (1998) said expert systems considered one of the key programs to emergence of $\mathrm{KM}$, where $\mathrm{KM}$ involves four functions: securing, creating, retrieving/combining, and distributing knowledge. Therefore, most of its roots can be found in the ES as well as artificial intelligence fields. However, the depending of most organizations on the development of an expert system is to all intents and purposes a repetitional process that characteristically needs turns of refinement, when in each round an expert and a knowledge engineer can dispense with impurities by purification of the knowledge base by comparing the human performance with the machine performance and imaginative human knowledge. This process necessarily needs to be repeated until the intended performance of the system is accomplished (Lavrac et al., 1989)

Consequently, the firms move towards the knowledge acquisition stage of ES that can capture and secure easily the knowledge left alone. Embryonic knowledge repositories for KM activities can be tracked to knowledge demonstration, methodologies, and knowledge 
encoding techniques in the ES. This is because the indexing of knowledge can be traced to even case retrieval, similarity, and adaptation methods applied in the case-based reasoning area of the expert systems field (Beydoun et al.1997, Lavrac et al., 1989). Thus, Loren et al. (2003) said that there is a wide-ranging presupposition that it is the companies that put together complex processes for the production of product or service, necessitating a balance of the generation of internal knowledge and the assimilation of external knowledge from the environment.

3) Executive support system (ESS): ESS "is an interactive computer system that provides business executives with the capability to obtain easy access to internal and external information relevant to decision-making and other executive actions" (Lee, S. M. et al., 1997). Accordingly, the executive support systems (sometimes called executive information systems - EIS) are different from other information systems and in many ways and considerations particular to the ESSs (Laudon et al., 1994; Rockart et al., 1988) as: "A) Designer clearly geared for the top management. B) Used by senior managers without a technical in the medium level. C) Require amount of greatest information from outside the project or business. D) Include structured data and unstructured together. E) Using various communication technologies such as texts, graphics ... etc."

In other words, the ESS systems are using all the tools available to provide information about the picture of organizational performance, while the DSS uses these tools mainly for the purposes of a lesser extent with respect to specific attitudes associated with them (Laudon et al., 1996). However, the companies focus on information of operating behaviour. This is because it indicates that those activities an ESS may engage in are searching, scanning, filtering, refining, interpreting, and presenting information for decision-making. This method has ability in information acquisition and the knowledge through scanning of the internal and external environment (Daft et al., 1988; Jones et al., 1993).

\subsection{The Efficiency}

The companies' view of business process KM (BPKM) is a Comprehensiveness approach for the purpose of individuals' management, operation, and technology and that has the ability to enhance operational fineness. Therefore, it may be thought that there is pairing between BPKM and KM, either of which element may be considered as a separate practice, but certainly not conflicting. As a process and knowledge are related and non-separate, this emphasizes the functional relationship between the two in order to support the possibility of success of the organization (http://jobfunctions.bnet.com/abstract.aspx?docid=1028577, 2009).

Thereby, in this context Sasson, J. et al., (2006) designed a model including three major repositories to knowledge. The first repository is a performance analysis repository, which is used to store analysis information. Before information is transferred to the repository for storage, users enter data through a performance analysis user interface. Users of the system can enter current state (or "IS") performance and compare it with desired (or "should") performance to identify and quantify performance gap for the efficiency improvement. 
When referencing any one of the repositories a user is able to access related items from any of the three repositories and by managing information in this format a user is able to find more relevant information in a more efficient manner. As we increase a user's ability to access information, we also increase the probability that they will actually do so, thereby increasing system utilization and achieving a higher return on investment for the system, removing the gap due to the collaboration between users to knowledge in the firm (Sasson, J. et al., 2006).

\section{Research Methodology}

This research sought to highlight the concept of KMS as an essential element, in which DSS and efficiency are elements that control the survival of organizations in the marketplace. The industry requires creative thinking to generate innovation, learning, and excellence in the knowledge cognition and acquisition, as well as spending in three types of DSS: GDSS, ESS, and ES for the purpose of the knowledge acquisition. It also requires investment in the learning and the investment in work teams for the purpose of access to cross-pollination of the ideas between the employees and to get on new ideas about the work. In other words, this research aimed to investigate the issues and factors that affect the utilization of $\mathrm{KM}$ as a catalyst for innovation and the learning organization to support decision-making for the efficiency improvement. Therefore, Decision models and DSSs which enhance effective utilization of this approach are investigated. A DSS that demonstrates an empirical application of KM will be developed through adopting the following objectives:

1. To investigate the role of KM as catalyst to learning for a creation of the innovation.

2. To develop a model of the KM and other factors into support of decisions that lead to the efficiency improving.

3. To test the model for significant decision factors to efficiency development.

4. To develop a guideline for establishing KMS for enhancing efficiency.

However, to achieve the study aims, Figures 3 and 4 are explaining the theoretical research model and the relationships among all the variables. 


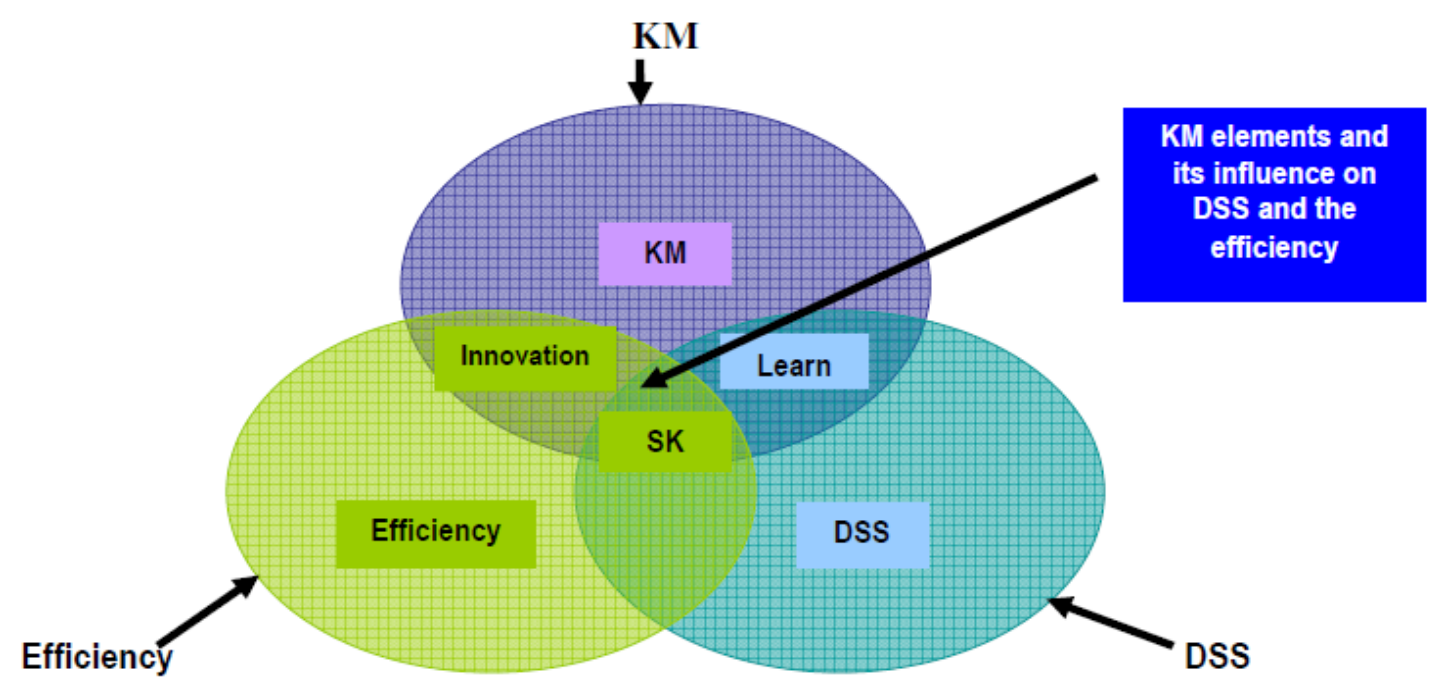

Figure 3: Theoretical Research Model

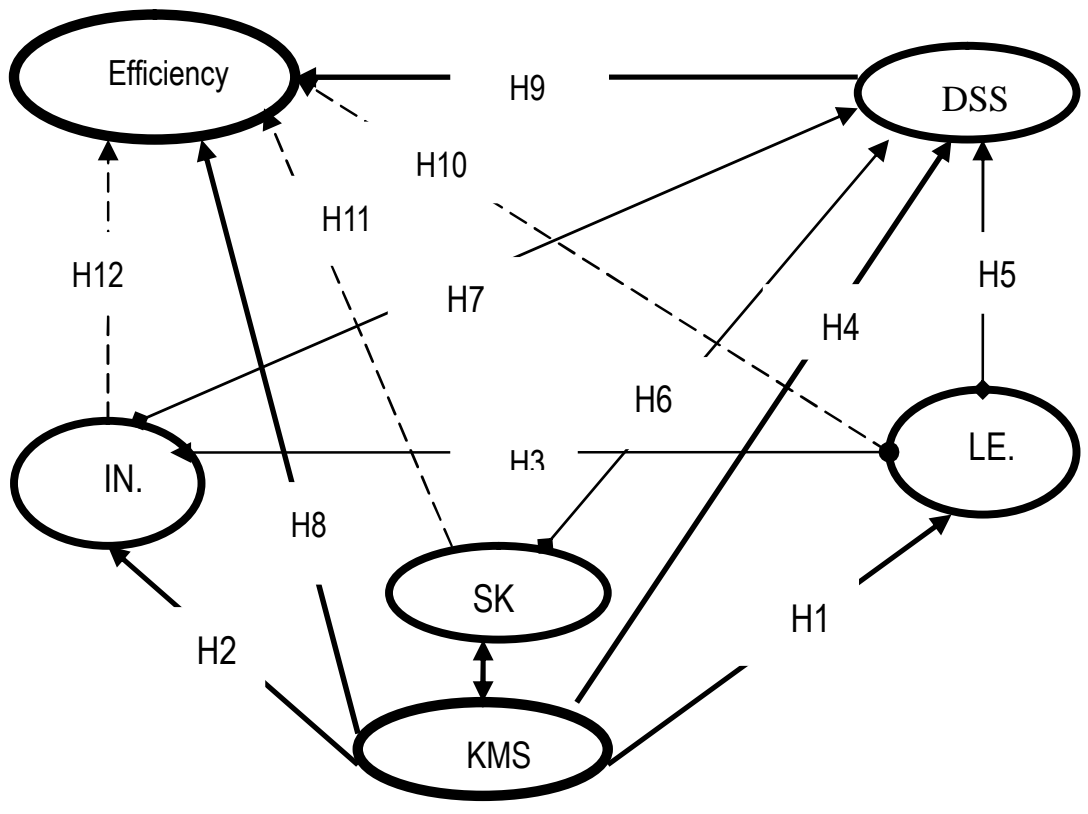

Figure 4: A Model of the Relationships Among the Variables

\subsection{Research Method}

This paragraph first explains research mechanism development and collecting data. The measurement model is then assessed, and research hypotheses are tested using regression coefficient, simple-correlation coefficient, and factor analysis with use of a test-adjusted $\mathrm{R}$ Square as well as Cronbach's $\alpha$ (SPSS software version 16), following the overall procedures displayed by the tables below. 


\subsection{Data Collection}

Knowledge learning and innovation is potentially constrained by knowledge sources and sorts of existing tools and the degree to which the culture of the organization encourages the spirit of sharing of the knowledge, in order to support DSS and enhance efficiency. Collected data was within several organizations in the UK, France, and Iraq, top managers and knowledge workers at the manufacturing departments. With advance technologies in manufacturing and globally distributed operations, they agreed to sponsor this study. Over and above that, the managers and workers have considered their organizations so that being in the early positions of KM efforts, this was requiring a limitation of sub-variables included in multiple knowledge sources.

Accordingly, the companies have seen that the experienced workers perhaps determine many of the knowledge sources. This is because they have known all of what was needed with it in practical experiences to perform the works in the firms. Consequently, cumulative experiences for long years must be transferring to new workers via learning for creation of innovation and enhancement of DSSs that reflect on efficiency.

Moreover, data was self-reported by employees in the questionnaire. This is because the knowledge considers fuzzy terms. For that reason, the questionnaire was extracted from employees' experiences as an expertise, thinking in the previous experiences and insights. Consequently, the questions within the questionnaire were a help in creation of a new vision of relationship among KM, DSS, ES, GDSS, ESS, and efficiency. Also there was a strong level of confirmation on the role of external knowledge resources in the organizations as not addressed so far.

\subsection{Setting out Data and the Results of Discussion}

In order to observe the role of KM in the learning and innovation performance of the firms in this study and to establish the factors affecting the DSS and the organizational performance, a Likert scale has been used that consists of five scales (Agreed, Mostly agreed, Neither agree nor disagree, Mostly disagree and Disagree).

For Validity Analysis in the stage of pre-test, the questionnaire survey was given to 15 experts at the manufacturing companies in the UK, France, and Iraq. Therefore, the validity of the questionnaire was verified in the research.

\subsection{Questionnaire Progress}

The reliability analysis by using Cronbach's Alpha Test results for the all variables was (0.89) for sample $=94$ according to equation as follows (Devellis, R.F. 1991):

$\alpha=\frac{k}{k-1}\left(1-\frac{\sum_{i=1}^{k} \sigma^{2} Y_{i}}{\sigma^{2} x}\right)$ 
Each with respect to the variable was as in Table 1 below:

Table 1: Reliability Statistics for the Companies

\begin{tabular}{|c|c|c|c|}
\hline Variable 1 & Variable 2 & No of Items & Cranbach's $\alpha$ \\
\hline KM & DSS & 2 & 0.84 \\
\hline LEA & INN & 2 & 0.97 \\
\hline $\mathrm{KM}$ & LEA & 2 & 0.95 \\
\hline KM & INN & 2 & 95 \\
\hline LEA & DSS & 2 & 61 \\
\hline INN & DSS & 2 & 0.61 \\
\hline SK & DSS & 2 & 0.65 \\
\hline $\mathrm{KM}$ & Efficiency & 2 & 0.65 \\
\hline INN & Efficiency & 2 & 0.67 \\
\hline LEA & Efficiency & 2 & 0.63 \\
\hline SK & Efficiency & 2 & 0.65 \\
\hline DSS & Efficiency & 2 & 0.84 \\
\hline GDSS & Efficiency & 2 & 0.84 \\
\hline ESS & Efficiency & 2 & 0.74 \\
\hline $\mathrm{ES}$ & Efficiency & 2 & 0.74 \\
\hline
\end{tabular}

This construct indicates consistency and stability in the questions, and for the all variables more than 0.60 indicates high reliability in the questionnaire to achieve aims of the research (Nunnally, 1978). This is because Cronbach's Alpha is widely believed to indirectly indicate the degree to which a set of items measures a single unidimensional latent construct. Revelle et al. (2006) have shown that Alpha can take on quite high values even when the set of items measures several unrelated latent constructs. 
Therefore as a result, Alpha is most appropriately used when the items measure different substantive areas within a single construct. When the set of items measures more than one construct, Coefficient Omega_Hierarchical is more appropriate (Zinbarg et al., 2005). Accordingly, Cronbach's Alpha test has explained to us that the question is validated for its reliability, when Cronbach's Alpha found as shown in Table 1. These are the values enabled to proceed further in this research areas, as the reliability of the questions found is very high.

\subsection{Standard Deviation}

In probability theory and statistics, the standard deviation of a statistical population, a data set, or a probability distribution, is the square root of its variance. Standard deviation is a widely used measure of the variability or dispersion, being algebraically more tractable though practically less robust than the expected deviation or average absolute deviation, and defined as follows (Yadolah, 2003):

$$
\delta N=\sqrt{\frac{1}{N}} \sum_{i=1}^{N}\left(x_{i}-\bar{X}\right)^{2}
$$

The questions have validated its reliability, where its standard deviation is found as explained in Tables 2 and 3 below to sample $(\mathrm{N}=94)$. Therefore, these values enabled proceeding further in these research areas, as the reliability of the questions found is very high.

Table 2: One-Sample Statistics for the Variables

\begin{tabular}{|c|c|c|c|c|}
\hline Variables & $\mathrm{N}$ & Mean & Std. Deviation & Std. Error Mean \\
\hline KM & 94 & 1.9142 & 0.40352 & 0.04162 \\
\hline DSS & 94 & 1.9676 & 0.51577 & 0.0532 \\
\hline LEA & 94 & 1.8777 & 0.42415 & 0.04375 \\
\hline INN & 94 & 1.9435 & 0.44242 & 0.04563 \\
\hline KS & 94 & 1.6622 & 0.38487 & 0.0397 \\
\hline Efficiency & 94 & 1.883 & 0.58854 & 0.0607 \\
\hline GDSS & 94 & 2.0864 & 0.60465 & 0.06236 \\
\hline ESS & 94 & 1.9113 & 0.60843 & 0.06276 \\
\hline ES & 94 & 1.8799 & 0.6062 & 0.06252 \\
\hline
\end{tabular}


Table 3: One-Sample Test for the Variables

\begin{tabular}{|c|c|c|c|c|c|c|}
\hline \multirow{2}{*}{ Components } & \multicolumn{2}{|c|}{} & \multicolumn{3}{c|}{ Test Value $=0$} \\
\cline { 2 - 7 } & & & & & \multicolumn{2}{c|}{$\begin{array}{c}\text { 95\% Confidence } \\
\text { Interval of the } \\
\text { Difference }\end{array}$} \\
\cline { 2 - 8 } & $\mathrm{t}$ & $\mathrm{df}$ & Sig. (2-tailed) & $\begin{array}{c}\text { Mean } \\
\text { Difference }\end{array}$ & Lower & Upper \\
\hline KM & 45.992 & 93 & .000 & 1.91418 & 1.8315 & 1.9968 \\
\hline DSS & 36.986 & 93 & .000 & 1.96758 & 1.8619 & 2.0732 \\
\hline LEA & 42.920 & 93 & .000 & 1.87766 & 1.7908 & 1.9645 \\
\hline INN & 42.590 & 93 & .000 & 1.94348 & 1.8529 & 2.0341 \\
\hline KS & 41.873 & 93 & .000 & 1.66223 & 1.5834 & 1.7411 \\
\hline Efficiency & 31.020 & 93 & .000 & 1.88298 & 1.7624 & 2.0035 \\
\hline GDSS & 33.455 & 93 & .000 & 2.08644 & 1.9626 & 2.2103 \\
\hline ESS & 30.457 & 93 & .000 & 1.91135 & 1.7867 & 2.0360 \\
\hline & 30.067 & 93 & .000 & 1.87994 & 1.7558 & 2.0041 \\
\hline
\end{tabular}

\subsection{Chi-Square Test}

According to Mood, et al, (1997) the Chi-Square Test is one of the statistical probability theories, being one of the most widely used in the distributions inferential statistics; for example, in assumptions testing over and above construction of confidence intervals to the data. In accordance with that, the method is defined as follows:

If $X_{1}, \ldots, X_{k}$ are independent, standard normal random variables, then the sum of their squares

$$
Q=\sum_{i=1}^{k} X i^{2}
$$

Is distributed according to the chi-square distribution with $k$ degrees of freedom. This is usually denoted as:

$Q_{\sim} X^{2}(K) o r Q X_{k}^{2}$ 
Accordingly, the chi-square distribution has one parameter: $k-$ a positive integer that specifies the number of degrees of freedom, i.e. the number of $X_{i}$ 's.

Consequently, the study has used this test to measure homogeneity of the sample data as explained by the results in Table 4 .

Table 4: Statistics of Chi-Square Test to the Variables

\begin{tabular}{|l|l|l|l|l|l|l|l|l|l|}
\hline component & KM & DSS & LEA & INN & KS & Efficiency & GDSS & ESS & ES \\
\hline Chi-Square & $15.426^{\mathrm{a}}$ & $79.872^{\mathrm{b}}$ & $\begin{array}{l}48.46 \\
8^{\mathrm{c}}\end{array}$ & $36.468^{\mathrm{d}}$ & $\begin{array}{l}34.68 \\
1 \mathrm{e}\end{array}$ & $73.872^{\mathrm{f}}$ & $51.106^{\mathrm{g}}$ & $\begin{array}{l}52.80 \\
9^{\mathrm{f}}\end{array}$ & $\begin{array}{l}76.59 \\
6^{\mathrm{h}}\end{array}$ \\
\hline $\mathrm{df}$ & 36 & 35 & 23 & 27 & 13 & 14 & 19 & 14 & 18 \\
\hline Asymp. Sig. & .999 & .720 & .781 & .811 & .691 & .730 & .810 & .770 & .680 \\
\hline
\end{tabular}

\subsection{Factor Analysis}

Factor analysis is a statistical method used to describe variability among observed variables in terms of a potentially lower number of unobserved variables called 'factors'. In other words, it is possible, for example, that variations in three or four observed variables mainly reflect the variations in a single unobserved variable, or in a reduced number of unobserved variables. Factor analysis searches for such joint variations in response to unobserved latent variables (Hatcher, 1994).Therefore, factor analysis of the companies of the study domain has found that all the employees confirmed in the first variable the inviting of the identification of knowledge management, creating a knowledge depository. There was obtained a percentage (98\%) from other variables, which has explained the Communalities for the Factor Analysis in Table 5. 
Table 5: Communalities: Extraction Method: Principal Component Analysis

\begin{tabular}{|c|c|c|}
\hline Variables & Initial & Extraction \\
\hline KM & 1.000 & .965 \\
\hline DSS & 1.000 & .902 \\
\hline LEA & 1.000 & .800 \\
\hline INN & 1.000 & .586 \\
\hline KS & 1.000 & .679 \\
\hline Efficiency & 1.000 & .660 \\
\hline GDSS & 1.000 & .669 \\
\hline ESS & 1.000 & .827 \\
\hline
\end{tabular}

However, the derived value for the contributing variable of knowledge management and DSS indicates that $97 \%$ from the variance in the values of the knowledge management are explained here as the common factors (the study has extracted two factors), where the value of contribution is ranging from $0-1$, which reflects the square-multiple-correlation coefficient to a variable of knowledge management with the factors. By and large, we note that the common factors explain a high percentage of the variables' variance. It was found to be less proportionate (59\%) to the variable of knowledge resources.

The following Table 6 highlights the latent roots of the matrix of correlations (the components' variance), and its total is equal to the rank of the matrix, which is an equal variable to the number of variables. The first main component has the largest latent root (or the component variance); equal to 4.911 and explains 54.567 from the total variance for variables of KM.

The second component is 23.897 of variance, explaining that the component is $78.464 \%$ from the variance structure to the 11 variables. And neglected in the program are the rest of the components, because the latent roots are less than one. The scree plot 5 is shown as well. The inflexion point to the curve has occurred after two factors explained in the table below from the total variances for variables of KM. This is because its roots are more than one. Either of the other factors neglected by the program is due to the latent roots being less than one. 
Table 6: Total Variance Explained to the all Variables

\begin{tabular}{|c|c|c|c|c|c|c|}
\hline \multirow[b]{2}{*}{ Component } & \multicolumn{3}{|c|}{ Initial Eigenvalues } & \multicolumn{3}{|c|}{$\begin{array}{c}\text { Extraction Sums of Squared } \\
\text { Loadings }\end{array}$} \\
\hline & Total & $\begin{array}{c}\% \text { of } \\
\text { Variance }\end{array}$ & $\begin{array}{c}\text { Cumulative } \\
\%\end{array}$ & Total & $\begin{array}{c}\% \text { of } \\
\text { Variance }\end{array}$ & $\begin{array}{c}\text { Cumulative } \\
\%\end{array}$ \\
\hline 1 & 4.911 & 54.567 & 54.567 & 4.911 & 54.567 & 54.567 \\
\hline 2 & 2.151 & 23.897 & 78.464 & 2.151 & 23.897 & 78.464 \\
\hline 3 & .697 & 7.740 & 86.204 & & & \\
\hline 4 & .434 & 4.821 & 91.025 & & & \\
\hline 5 & .401 & 4.454 & 95.479 & & & \\
\hline 6 & .271 & 3.009 & 98.488 & & & \\
\hline 7 & .135 & 1.504 & 99.992 & & & \\
\hline 8 & .001 & .008 & 100.000 & & & \\
\hline 9 & $-2.736 E-16$ & $-3.040 \mathrm{E}-15$ & 100.000 & & & \\
\hline
\end{tabular}

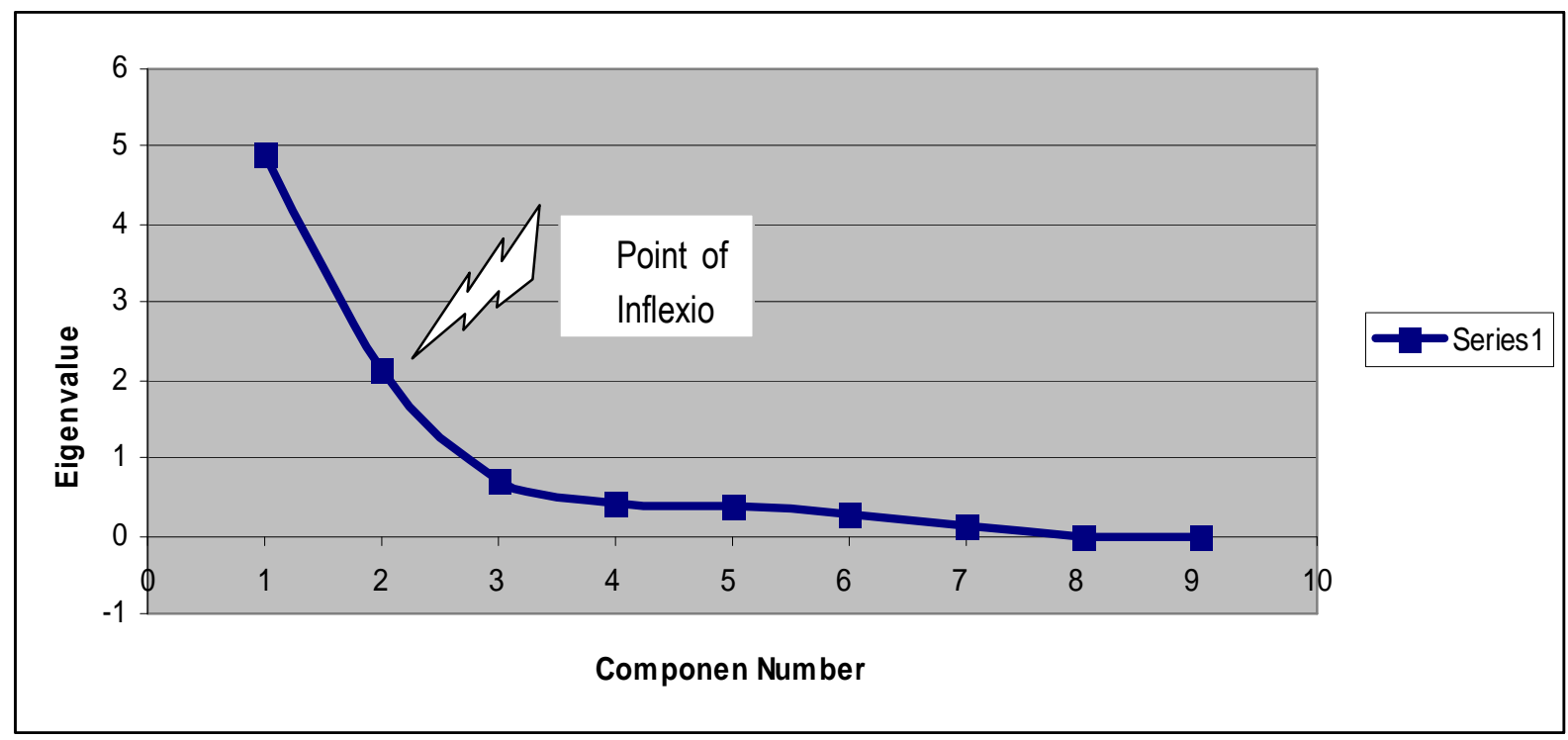

Figure 5: Scree Plot to the Inflexion Point in the Curve (Source: Table 6) 
Over and above that, Table 7 below represents the components' matrix that includes the loadings of ramifications of the components 1 and 2 that have been explained in previous analysis, where the ramifications represent a simple correlation of coefficients among the components. Analysis of the results highlighted that the most powerful variables that are correlated with the first factor are variables of DSS, Creativity, GDSS, ESS and Learning, when the percentages of both variables were 0.87 and $0.77,0.76,0.74$ and 0.65 respectively.

Then the variable is the performance 0.73 and ES 0.72 . The weakest variable of correlation with the first variable is ES 0.578. Accordingly, we have noted that the Slope of the line changes dramatically. Therefore, in Figure 4 we envisage drawing a straight line that recapitulates the vertical part of the Scree plot and another that summarizes the horizontal part.

The point of inflexion to data point is where these two lines meet. Hence, factor analysis has elicited two factors. Hereby, we retain or extract only factors to the left of point of inflexion and do not include the factor at the point of inflexion itself. With a sample of more than 94 participations, the scree plot provides a fairly reliable criterion for factor selection that is explained in the above analysis values and for all the variables.

Table7: Component Matrix ${ }^{\mathrm{a}}$

\begin{tabular}{|c|c|c|}
\hline \multirow{2}{*}{ Components } & \multicolumn{2}{|c|}{ Component } \\
\cline { 2 - 3 } & 1 & 2 \\
\hline KM & .770 & .610 \\
\hline DSS & .872 & -.462 \\
\hline LEA & .654 & .689 \\
\hline INN & .765 & .463 \\
\hline KS & .603 & .471 \\
\hline Efficiency & .729 & -.384 \\
\hline GDSS & .759 & -.291 \\
\hline ESS & .741 & -.346 \\
\hline ES & .723 & -.551 \\
\hline
\end{tabular}

Extraction method: principal component analysis

a: 2 components extracted 
In view of that, with the factor analysis result's it appears that there is a major concern for the employees about identification of appropriate knowledge resources for their works and how these are learned within the corporation. Their focus is on knowledge transfer perspective, i.e. focusing more on facilitation of internal knowledge flow rather than observing initiatives in knowledge identification. Further to that, the learning behaviour evolves through time, because knowledge exchanges tend to occur between employees who appear to have the capability for learning quickly during the cross-pollination of ideas in the workplace. Furthermore, the analysis for the variables has explained the role of KM in innovation, where the KM's value over time increases the process of innovation to ensure efficiency and effectiveness in the organization's processes.

\section{Measuring Of Relationship between the Variables of Study}

This section focuses on the determination of the type of relationship (correlation) and its strength between independent study variables $\left(\mathbf{X}_{\mathbf{i}}\right) \mathrm{KM}$; the dependent study variables that are represented by DSS and Performance (Yi) in this study are defined as follows:

$\mathbf{X}_{\mathbf{1}}$ : KM, $\mathbf{X}_{\mathbf{2}}$ : Sourcing Knowledge/Internally and Externally, $\mathbf{X}_{\mathbf{3}}:$ Innovations, $\mathbf{X}_{\mathbf{4}}$ : Learning, $\mathbf{X}_{5}:$ GDSS, $\mathbf{X}_{6}:$ ESS, $\mathbf{X}_{7}:$ ES, $\mathbf{Y}_{1}:$ DSS, $\mathbf{Y}_{2}:$ Efficiency.

In order to determine the type and strength of the relationship between any of the various indicators of DSS and OP $\left(\mathbf{Y}_{\mathbf{i}}\right)$ variables and all independent variables in the study $\left(\mathbf{X}_{\mathbf{i}}\right)$ we have relied on the simple correlation coefficient (Pearson), which has the symbol $\left(\mathbf{r}_{\mathbf{x y}}\right)$. This depended on the statistical program ready [SPSS Ver 16 under system (Windows-2003)], and Excel software to have elicited $\left(\mathbf{R}^{\mathbf{2}}\right)$ by using polynomial method. Table 8 (see below) hence explains all the results.

\subsection{Model Specification}

Before beginning the process of assessing the relationship, we must characterize the standard model of the relationship between the variables of the study and selection of the best models, as follows:

\section{Firstly: Linear Model}

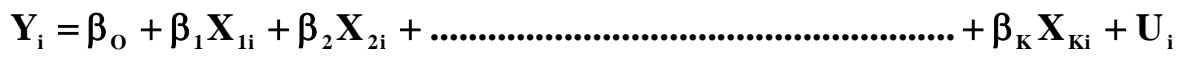

\section{Secondly: Logarithmic model}

$\log Y_{i}=\log \beta_{0}+\beta_{1} \log X_{1 i}+\beta_{2} \log X_{2 i}+\ldots \ldots \ldots \ldots \ldots \ldots+\beta_{K} \log X_{K i}+\log U_{i}$

\section{Thirdly: Semi-Logarithmic Model}

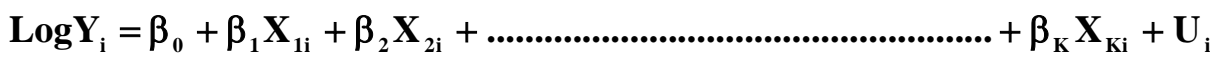

\section{Fourthly: Logarithmic-inverse Mode}


$Y_{i}=\log \beta_{0}+\beta_{1} \log X_{1 i}+\beta_{2} \log X_{2 i}+\ldots \ldots \ldots \ldots \ldots \ldots \ldots \ldots+\beta_{K} \log X_{K i}+\log U_{i}$

\section{Fifthly: Polynomial Model}

\begin{tabular}{|c|c|c|c|c|}
\hline & & \\
\hline & & \\
\hline \multicolumn{4}{|l|}{$\mathbf{a}_{\mathbf{n}} \mathbf{x}^{\mathbf{n}}+\mathbf{a}_{\mathbf{n}-1} \mathbf{x}^{\mathbf{n}-1}+\cdots$} & \\
\hline
\end{tabular}

\section{Sixthly: Cubic Model}

$Y_{i}(t)=a_{i}+c_{i} t^{2}+d_{i} t^{3}$

To get the best multiple-regression model between the models explained above, which include a number of the independent variables $\left(\mathrm{X}_{\mathrm{i}}\right)$ that explain as well as possible the changes in the dependent variables $\left(\mathrm{Y}_{1}, \mathrm{Y}_{2}\right)$, we have used a backward elimination procedure method that is based on the use of the full equation of the model. Then a variable is eliminated, one in each stage, that has little influence in the model on the dependent variable (Y) in succession. In other words, we delete one variable at each stage based on its small contribution, thereby reducing the sum of squares of errors $\left(\sum \mathbf{U i}^{2}\right)$ to all variables.

In comparison, the values of the statistical variables and the standards to estimated models for $\mathrm{Y}_{1}$ and $\mathrm{Y}_{2}$ in Table 8 indicate the chosen optimal model, the cubic model. The regression of the polynomial model to $\mathrm{R}^{2}$ exceeds all of the statistical tests and the entire standard.

Table 8: The Results of the Statistical Analysis

\begin{tabular}{|c|c|c|l|c|c|}
\hline \multirow{2}{*}{ Variables } & $\mathrm{R} \%$ & $\mathrm{r}_{\mathrm{xy} \%}$ & $\begin{array}{l}\text { Adjusted } \\
\text { Square }\end{array}$ & & \multicolumn{2}{|c|}{$\mathrm{R}$. Test } \\
\cline { 4 - 6 } & & & & The calculated value & $\begin{array}{l}\text { The } \\
\text { tabulated } \\
\text { value }\end{array}$ \\
\hline KM \& DSS & 0.60 & $0.89 * *$ & 0.64 & 17.12 & 3.119 \\
\hline $\begin{array}{c}\text { Leaning \& } \\
\text { Innovation }\end{array}$ & 0.73 & $0.72 * *$ & 052 & 50.50 & 3.119 \\
\hline $\begin{array}{c}\text { KM\& } \\
\text { Learning }\end{array}$ & 0.92 & $0.91 * *$ & 0.84 & 158.30 & 3.119 \\
\hline KM \& & 0.94 & $0.94 * *$ & 0.88 & 346.83 & 3.119 \\
\hline
\end{tabular}




\begin{tabular}{|c|c|c|c|c|c|}
\hline Innovation & & & & & \\
\hline $\begin{array}{l}\text { Learning \& } \\
\text { DSS }\end{array}$ & 0.68 & $0.60 * *$ & 0.55 & 16.73 & 3.119 \\
\hline $\begin{array}{c}\text { Innovation \& } \\
\text { DSS }\end{array}$ & 0.63 & $0.56^{* *}$ & 0.67 & 19.54 & 3.119 \\
\hline SK\& DSS & 0.69 & $0.52 * *$ & 0.55 & 5.407 & 3.119 \\
\hline $\begin{array}{c}\text { KM \& } \\
\text { Efficiency }\end{array}$ & 0.54 & $0.72 * *$ & 0.57 & 12.613 & 3.119 \\
\hline $\begin{array}{c}\text { Innovation \& } \\
\text { Efficiency }\end{array}$ & 0.55 & $0.76^{* *}$ & 0.54 & 12.998 & 3.119 \\
\hline $\begin{array}{l}\text { Learning \& } \\
\text { Efficiency }\end{array}$ & 0.66 & $0.58 *$ & 0.52 & 8.197 & 2.2541 \\
\hline $\begin{array}{c}\text { SK \& } \\
\text { Efficiency }\end{array}$ & 0.58 & $0.59 * *$ & 0.51 & 5.01 & 3.119 \\
\hline $\begin{array}{c}\text { DSS \& } \\
\text { Efficiency }\end{array}$ & 0.74 & $0.73 * *$ & 0.53 & 36.55 & 3.119 \\
\hline $\begin{array}{c}\text { GDSS \& } \\
\text { Efficiency }\end{array}$ & 0.61 & $0.58 * *$ & 0.55 & 17.76 & 3.119 \\
\hline $\begin{array}{c}\text { ESS \& } \\
\text { Efficiency }\end{array}$ & 0.61 & $059 * *$ & 0.58 & 18.09 & 3.119 \\
\hline $\begin{array}{c}\text { ES \& } \\
\text { Efficiency }\end{array}$ & 0.69 & $069 *$ & 0.56 & 27.78 & 2.2541 \\
\hline
\end{tabular}

Figure 6 explains the relationship among the variables based on the results that are displayed in Table 8 for each than the regression and adjusted $\mathrm{R}$ square. Relationship results have presented a foothold and also display new insight in this research about the incorporation with other KM theory, e.g. a test of the relationship between knowledge acquisition and knowledge learning and sharing for a creation of cross-pollination to the ideas between workers. This is because it is helping in sourcing knowledge that is useful to the organizations. 


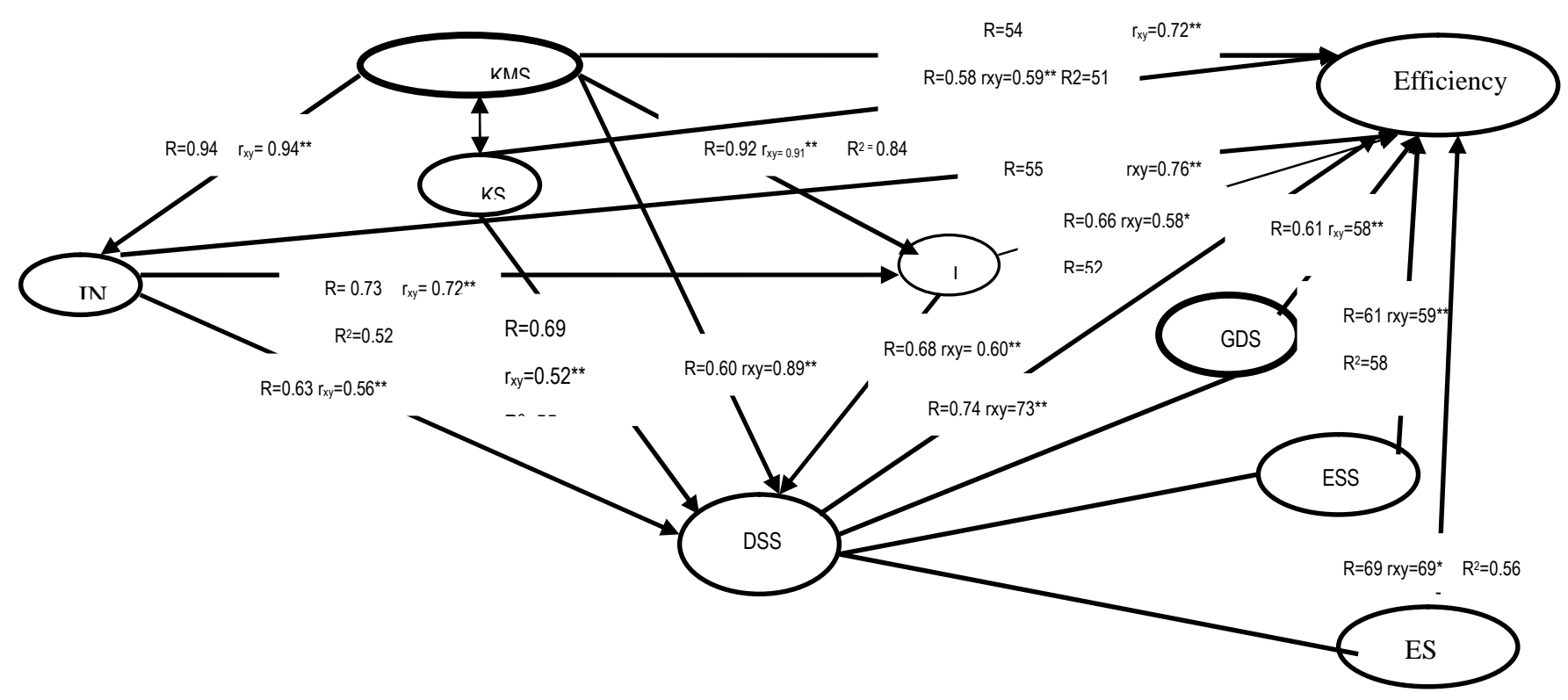

Figure 6: Standardized Structural Parameters in a Model of KM and the Sub-independent variables with DSS and Efficiency (source: Table 8)

However, the results analysis appears to display that the product learning is creating sustainable innovation to the firms. This is because of a lead to cross-pollination of the new ideas and is ensuring sharing and transferring of knowledge within organization departments. In explaining the computerised statistical analysis of the simple correlation coefficient (rxy) between KM and learning and innovation and the factors influencing them, the independent variable $\left(\mathrm{X}_{\mathrm{i}}\right)$, Sourcing Knowledge $(\mathrm{SK})$ generated the following conclusions: the simple correlation coefficient (rxy) between $\mathrm{KM}$ and the learning $\left(\mathrm{X}_{4}\right)(0.91 * *)$ means that there is a very strong and direct correlation between $\mathrm{KM}$ and $\mathrm{X}_{4}$. This means that any increase in $\mathrm{KM}$ will lead to a significant increase in $\mathrm{X}_{4}$, and vice versa. On the other hand, it is observed that the simple correlation coefficient ( $\mathrm{rxy}=0.91 * *)$ is at the moral level statistically $(0.01)$. Figure 5 explains the relationship in regression between the variables below according to a cubic model. The simple correlation coefficients between $\mathrm{KM}$ and innovation $\left(\mathrm{X}_{3}\right)$, and between learning $\left(\mathrm{X}_{4}\right)$ and innovation $\left(\mathrm{X}_{3}\right),(0.94 * *, 0.72$ respectively) indicate a direct and strong correlation between these variables.

This means that the companies are focusing on learning as a part from top strategy to the organization, for the purpose of sharing and transfer of acquired knowledge of previous experiences during the learning process, transferring it to the product innovation process within the company work. Over and above that, the firms look forward to the acquiring and promulgation of the external knowledge in the organizational levels through a computer-based methodology, assessing organizational knowledge capture and transfer in the new products development process. This requires a depending on expert systems because they have the ability to create knowledge repository for the support of senior management in potential problem-solving from some knowledge resources that can be stocked in the program 
memory.

It has also found strong and medial correlation relationships among $\mathrm{KM}, \mathrm{X}_{2}, \mathrm{X}_{3}, \mathrm{X}_{4}$ and DSS, where there were the values of $0.89^{* *}, 0.52 * *, 0.56^{* *}$ and $0.60 * *$ respectively, with moral levels of 0.01 . That means, an increase in any of the above variables (or a combination of them) will lead to an increase in DSS, and vice versa.

Additionally, the simple correlation coefficients between efficiency and $\mathrm{X}_{1} \mathrm{KM}, \mathrm{X}_{2}$ Sourcing Knowledge, $\mathrm{X}_{3}$ Innovations, and $\mathrm{X}_{4}$ Learning $\left(0.72^{* *}, 0.59^{* *}, 0.76^{* *}\right.$ and $0.58^{*}$, respectively) and with moral levels ( 0.01 and 0.05$)$ indicate a direct and strong correlation between these variables. Therefore, an increase in any of the above variables (or a combination of them) will lead to an increase in efficiency, and vice versa.

Furthermore, the coefficients are moral with level $(0.05,0.01)$. The simple correlation coefficients between efficiency and DSS, GDSS $\left(\mathrm{X}_{5}\right)$, ESS $\left(\mathrm{X}_{6}\right)$, and ES $\left(\mathrm{X}_{7}\right)\left(0.73^{* *}, 0.58^{* *}\right.$, $0.59^{* *}$, and $0.69 *$, respectively) indicate a direct and strong correlation between these variables. Thus they explain in the regression a relation among dependent variable efficiency and the independent variables $\left(\mathrm{X}_{5}, \mathrm{X}_{6}, \mathrm{X}_{7}\right)$. Therefore, an increase in any of the above variables (or a combination of them) will lead to an increase in $\mathrm{Y}_{2}$, and vice versa. However, the coefficients are moral with level $(0.05,0.01)$, and to make sure the statistical moral to the regression coefficients $(\hat{\boldsymbol{\beta}})$ was used as the test $(\mathrm{t})$, to test the following two hypotheses:

\section{Ho: ${ }^{\beta}=0$, Vrs.}

$\mathrm{H}_{1}: \beta \neq \mathbf{0}$

We have found all significant regression coefficients of the cubic model as explained in Table 8 to all the relations below. By comparing the absolute values for $(|\mathbf{t}|)$ calculated values to all coefficients $(\hat{\beta})$, and by comparing tabular values by freedom degree (93) and the level of moral $(0.05,0.01)$, has confirmed that the value $(|t|)$, the calculated absolute value, greater than the tabular value for all variables at the level indicated by the null hypothesis that will be rejected as null hypothesis $\left(\mathrm{H}_{\mathrm{O}}\right)$, and will accept the alternative hypothesis $\left(\mathbf{H}_{\mathbf{1}}\right)$.

This means that there is a statistically significant effect with high degree at the moral level $(0.05,0.01)$ to all the independent variables $\left(\mathrm{X}_{\mathrm{i}}\right)$ on the dependent variables (Yi) - (DSS and efficiency). We have explained through the value of the coefficient of the adjusted determination $\left(\mathrm{R}^{2}\right)$ which was highlighted in Table 3 to the all the independent variables $\left(\mathrm{X}_{\mathrm{i}}\right)$ represented by (KM, Sourcing Knowledge $\mathrm{X}_{2}$, innovation $\mathrm{X}_{3}$, learning $\mathrm{X}_{4}$, GDSS $\mathrm{X}_{5}, \mathrm{ESS}$ $\mathrm{X}_{6}$, and $\mathrm{ES}_{7}$ ) and the dependent variables (DSS, efficiency). It was able to interpret the changes that occur at the dependent variables according to percentages highlighted in Table 8 . The other percentages either return to the deleted variables and the other variables which are 
not included in the model. To determine the moral of statistical cubic regression model generally, we have adopted the statistical test $(\mathrm{F})$ to test the following two hypotheses:

\section{$\mathrm{H}_{0}$ : The model is not significant.}

\section{Vrs. $\quad \mathbf{H}_{1}$ : The model is significant}

It is explained that the calculated values (Fcal.) are greater than the value of tabular to all the variables as in Table 8, with the degree of the freedom to the numerator and denominator $(9$, 94) and with the level of moral (0.05 and 0.01). This means that the null hypothesis will be rejected $\left(\mathrm{H}_{0}\right)$, and the alternative hypothesis $\left(\mathrm{H}_{1}\right)$ accepted. This indicates that the cubic model is highly statistically significant at the level of moral $(0.05,0.01)$. Thus, the cubic model is highly efficient in the treatment of the data that we have collected in this study, and can be used for the purposes of forecasting with DSS and efficiency in the future case. We discover whether the model has multiple problems by testing two hypotheses. According to Montgomery et al. (2001), most regression problems involving time series data exhibit positive autocorrelation, so the hypotheses usually considered in the Durbin-Watson test are:

$$
\begin{aligned}
& H_{0}: \hat{\mathbf{p}}=\mathbf{0} \\
& H_{1}: \hat{\mathbf{p}} \neq \mathbf{0}
\end{aligned}
$$

The statistical test is;

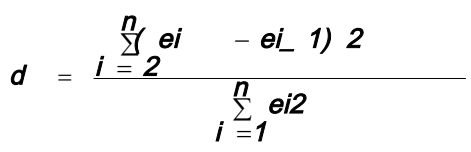

Where ei $=$ yi $-{ }^{\text {`yi, }}$ and yi and `yi are, respectively, the observed and predicted values of the response variable for individual i. ' $d$ ' becomes smaller as the serial correlations increase. Upper and lower critical values, $\mathrm{dU}$ and $\mathrm{dL}$, have been tabulated for different values of $\mathrm{k}$ (the number of explanatory variables) and $\mathrm{n}$ :
If $\mathrm{d}<\mathrm{dL}$
reject $\mathrm{H}_{0}: \mathrm{p}=0$
If $\mathrm{d}>\mathrm{dU}$
do not reject $\mathrm{H}_{0}: \mathrm{p}=0$
If $\mathrm{dL}<\mathrm{d}<\mathrm{dU}$
test is inconclusive.

It appeared from the results that the value of (DW) as calculated for the cubic model has been for all variables, where the value of Durbin-Watson was calculated (1.895). Table 9 highlighted these values to DW and compared that value with the two limits, the lower (dL) and the upper $(\mathrm{dU})$, the tabular at moral level $(0.01$ and 0.05$)$, and the number of independent 
variables $(\mathrm{K}=8)$ and the sample size $(94)$ and the equal to $(\mathrm{dL}=1.358)$ and $(\mathrm{dU}=1.715)$ consecutively. There the value of (DW) the tabular among (1.358-1.715) is located within the domain $(\mathrm{dU}<\mathrm{D} . \mathrm{W} .<4-\mathrm{dU})$, i.e. $(1.715<D . W .<3.073)$.Therefore, we will accept the null hypothesis (Ho), meaning that the cubic model does not suffer from the problem of self-correlation between the values of random variables (Ui).

Table 9: Model Summary to the Durbin-Watson

\begin{tabular}{|c|c|c|c|c|c|}
\hline Model & $\mathrm{R}$ & R Square & $\begin{array}{c}\text { Adjusted R } \\
\text { Square }\end{array}$ & $\begin{array}{c}\text { Std. Error of the } \\
\text { Estimate }\end{array}$ & Durbin-Watson \\
\hline 1 & $.999^{\mathrm{a}}$ & .999 & .999 & .01396 & 1.895 \\
\hline
\end{tabular}

\subsection{P-P Plots}

The plot test is used in this study in order to determine in this research whether the distribution of a variable matches a given normal distribution. If the selected variable matches the test distribution, the points cluster around a straight line. This case has explained all the variables analysis for us, and the points cluster around an approximately straight line for all the variables, as shown in Figures 7-15. This indicates a normal distribution to the study data, and is consistent with the analysis and tests in the study previously.

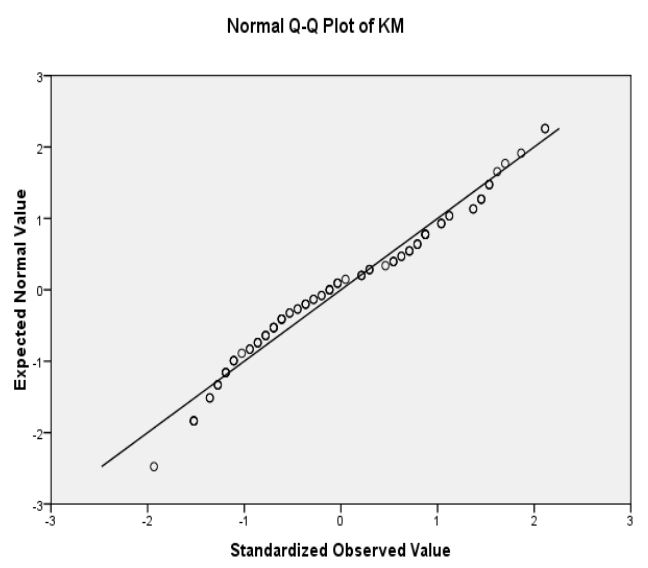

7: P-Plot distribution for the KM

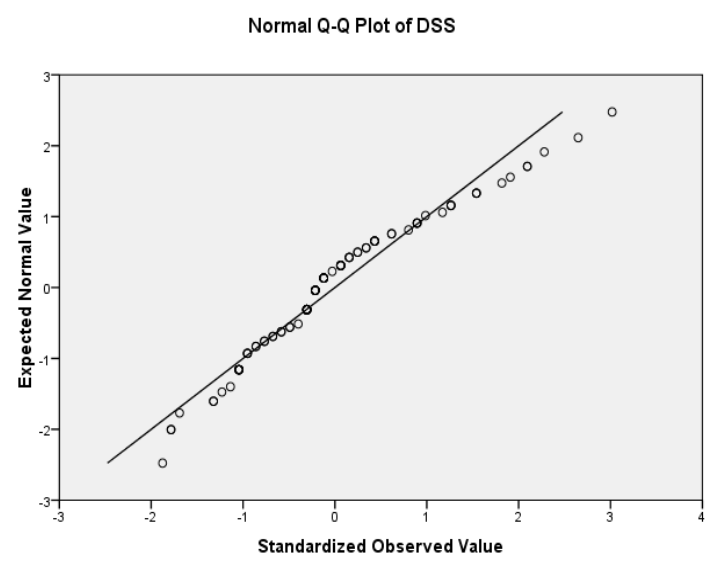

Figure 8: P-Plot for the DSS 


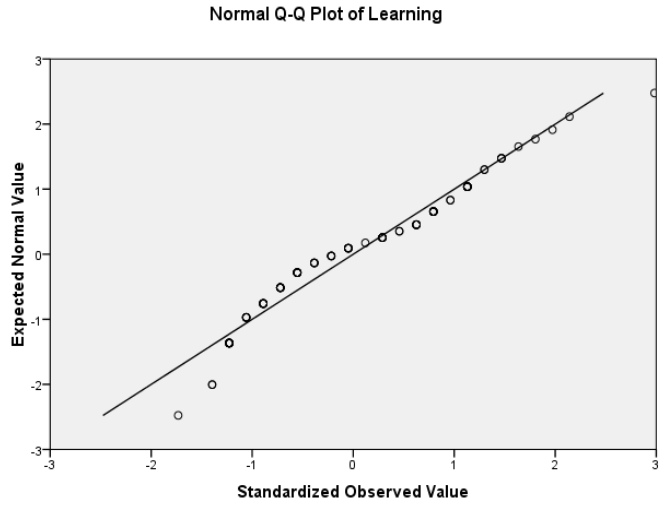

Figure 9: P-Plot for the LE

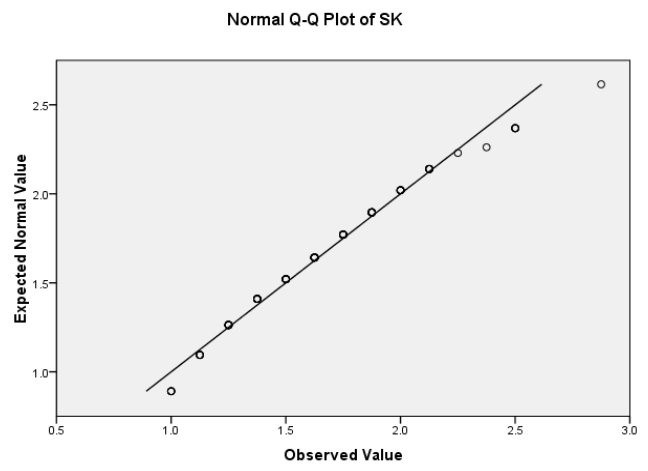

Figure 11: P-Plot for the SK

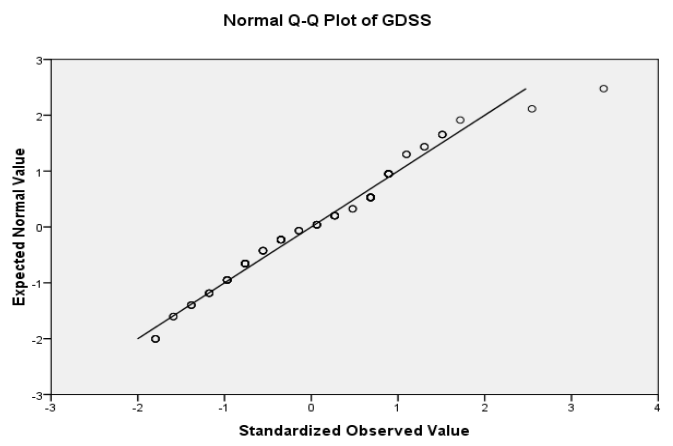

Figure 13: P-Plot for the GDSS

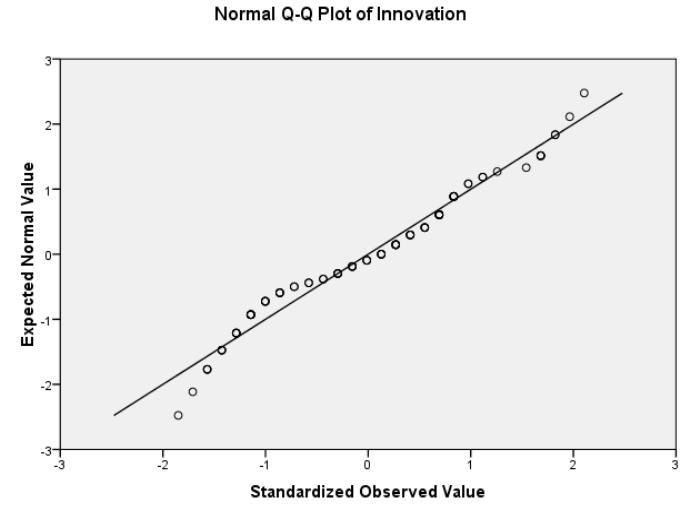

Figure 10: P-Plot for the INN.

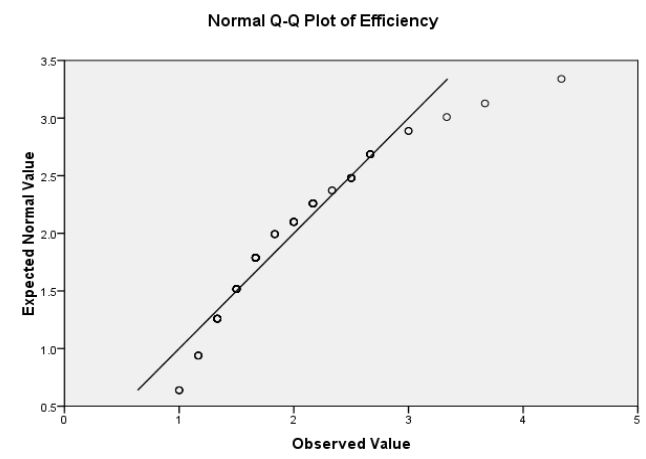

Figure 12: P-Plot for the Efficiency

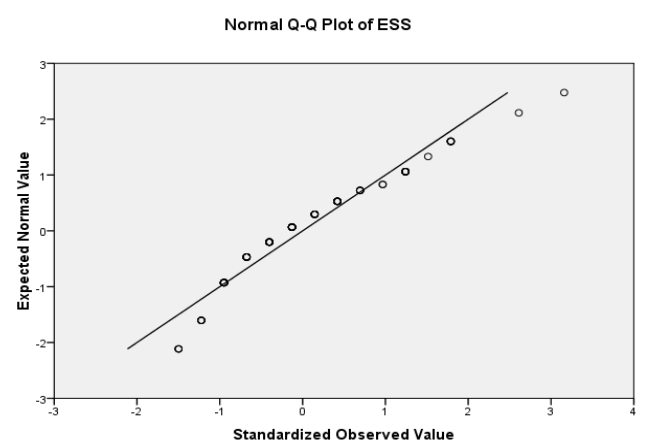

Figure 14: P-Plot for the ESS 


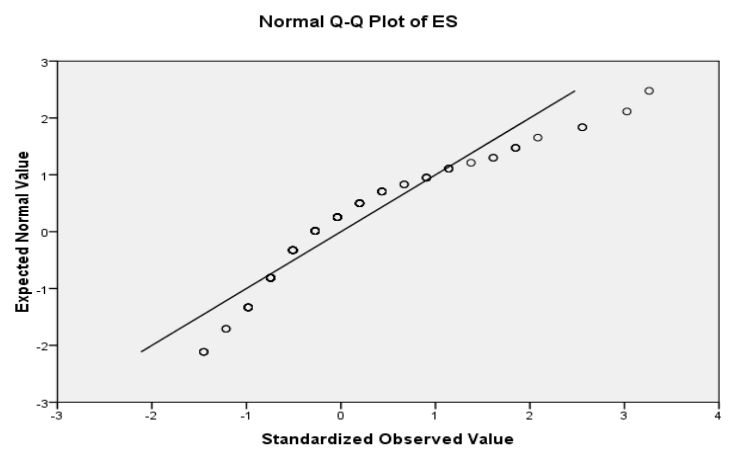

Figure 15: P-Plot for the Expert Systems

Additionally, the P-Plot tests have been explained and presented for a high-resolution about the nature of questions and its consistency. This aimed to show the minds of employees for the purpose of production of relationship among the study variables. Also this tool assists in identifying which cases lie above and below the regression line. On the other hand, using correlation to describe relationships between all the variables is explaining a high correlation requiring validation. Therefore, the relationship and the study model, where the line of the relationship was almost ( $\mathrm{x}=\mathrm{y})$ at 45 degrees (Field, A., 2009).

\section{Conclusions}

In this search we have wanted to evaluate the matter of how learning could be a way to organizational innovation, i.e. that exploration and exploitation of the internal experiences and external practical experiences from the organizations can improve new workers' ability in creation of innovation and be comparative between them. Moreover, we obtained some peripheral results which are worth paying attention to. We can sum up that relying on prior knowledge is helping for the future of companies by providing practical experiences in the way to engage organizational learning for creative work. In return, it has been proved that sourcing knowledge has a positive effect on both innovation and competitiveness. On the other hand, using former experience can help an enterprise to boost learning. This statement is in line with the quote that says 'experience is the best science'.

Consequently, this requires there being a delimitation to the constitutive reasons for the innovation, through adopting the significance of implicit knowledge to creative works. This requires a focus on the workers that are creating and circulating knowledge between company divisions and the employees. On the other hand, this research has tried to assess the design and analysis of the relationships among KMS, Learning, Innovation, sourcing knowledge, and DSS, GDSS, ESS, ES, as well as the efficiency. The relationships between the variables highlighted confirm that the expert systems have the capacity to improve and create highly efficient and beneficial data depository based on KM for the purpose of decision-making support. Where the expert systems are made according to Buchanan et al. (1983) they depend on the knowledge acquisition for a transfer and transformation of potential problem-solving expertise from knowledge sources to the program, on the basis of analyzing factors that affect efficiency. Where this is found could provide support to senior management for sponsoring 
the knowledge sharing, in order to ensure high efficiency in the work and achieve the final aim by competitiveness.

\section{Research Implication}

This preliminary study is detailed enough to be deemed completely reliable. In view of this, this research has presented significant contributions to both theory and practice. On the theoretical side the research has discovered some factors of critical KM that is using as Catalyst for Innovation and Organizational Learning Support in Decision-Making for Efficiency Improvement. In conclusion, it provides data that can be used essentially as the basis of the main investigation. On this premise, this case study could be implemented on mechanical, systems engineering, and manufacturing industries. This is because the findings have been tested where primary aims to this research that has tied together the concept of knowledge management (KM), decision support system (DSS) and efficiency as a way of creation of continuable competitive advantage for the firms. let alone, A conceptual model is extracted from the literature review, developed and supported by knowledge experiences of senior workers in companies that have been adopted in the study. Additionally, the research has examined the current use of KM tools and assessed the most prominent methods. Furthermore, this paper has addressed the examined objectives by providing an explanation of several issues; identifying the key sources of $\mathrm{KM}$ and the corresponding factors. Given that, the examining KM is found to occur most strongly over the stages of manufacturing and on which high level KM mainly occurs.

\section{FUTURE WORK}

One of the more significant findings emerging from this study is that we have wanted to evaluate the matter of how learning could be a way to organizational innovation, i.e. that exploration and exploitation of the internal experiences and external practical experiences from the organizations can improve new workers' ability in creation of innovation and be comparative between them. Moreover, we obtained some peripheral results which are worth paying attention to. We can sum up that relying on prior knowledge is helping for the future of companies by providing practical experiences in the way to engage organizational learning for creative work. In return, it has been proved that sourcing knowledge has a positive effect on both innovation and competitiveness. On the other hand, using former experience can help an enterprise to boost learning. This statement is in line with the quote that says 'experience is the best science'.

Consequently, an initial study with consolidating firms that are effective in the industrial sector of the world was a lead to validating the study model and smoothing the progress of achieving investigation of the adopted relationships by the study. Collecting data was completed via interviews with managers and knowledge workers of the firms in addition to use of the survey questionnaire which was distributed to random samples from these firms.

Further experimental investigations are needed there being delimitation to the constitutive reasons for the innovation, through adopting the significance of implicit knowledge to creative works. This requires a focus on the workers that are creating and circulating 
knowledge between company divisions and the employees. in other words, assess the design and analysis of the relationships among KMS, Learning, Innovation, sourcing knowledge, and DSS, GDSS, ESS, ES, as well as the efficiency. The relationships between the variables could highlights that the expert systems have the capacity to improve and create highly efficient and beneficial data depository based on KM for the purpose of decision-making support. Where the expert systems are made according to Buchanan et al. (1983) they depend on the knowledge acquisition for a transfer and transformation of potential problem-solving expertise from knowledge sources to the program, on the basis of analyzing factors that affect efficiency.

More broadly, research is also needed to conduct survey, but with bigger size of the samples and companies to validate it experimentally. It would be interesting to assess the effects of new survey in gaining more powerful tools and then follow-up of the quantitative research findings analysis. Moreover, this analysis will provide widely technical knowledge and expertise needed to select and apply the most appropriate knowledge in the organization. That means, through analysis of "new survey" the companies can be described with the difference between the enterprise's current capability and the capabilities required for knowledge management. These findings will allow for the development of tangible dimension indices for the knowledge acquisition.

\section{Acknowledgement}

This research has been Supported by the European organizations, and the Iraqi organizations, through the Manufacturing Firms. Therefore, the author wishes to acknowledge those companies' support, and their contribution during the development of ideas and concepts suggested in this research.

\section{References}

Alavi, M. and Leidner, D.E. (2001), 'Knowledge management and Knowledge Management System: Conceptual Foundations and Research Issues, MIS Quarterly, Vol. 25, No. 1. , pp. $107-146$

Andrew, I. (1998) Learning and knowledge acquisition through international strategic alliances, Academy Management Journal.

Argyris, C. and Schon, D. (1978) Organizational Learning: A Theory of Action Perspective, Addison-Wesley, Reading, MA.

Auernhammer, K. and Leslie, A. Neumann, M. and Lettice, F. (2003) Creation of Innovation by Knowledge Management -A case study of a learning software organisation, PP: $53-57$

Beydoun, G. and Hoffmann, A. (1997) NRDR for the Acquisition of Search Knowledge, Vol. 1342, PP: 177-186.

Buchanan, B. G. and Barstow, D. and Bechtel, R. and Bennet, J. and Clancey, W. and Kulikowski, C. and Mitchell, T. M., and Waterman, D. A., (1983), Constructing An Expert 
System”, In Hayes-Roth, F. and Waterman, D. A. and Lenat D., (1983), Building Expert Systems, Teknowledge Series In Knowledge Engineering, Addison Wesley, Reading, Massachusetts, USA..

Busch, P. and Richards, D. (2006) Innovation Knowledge Acquisition: The Tacit Knowledge of Novices, PP: 259-268.

Charles, C. Emery, J. (1994) Reengineering the Requirements Process for Executive Support System Development using an Electronic Meeting System, Proceedings of the Twenty-Seventh Annual Hawaii International Conference on System Sciences, PP: 41-50.

Chryssolouris, G., and Mourtzis, D. and Papakostas,N.,and Papachatzakis, and Xeromerites Z. (2008), Knowledge Management Paradigms in Selected Manufacturing Case Studies , Springer.PP:521-532.

Crossan, M.M. and Lane, H.W. and White, R.E. (1999) An Organizational Learning Framework: from Intuition to Institution, Academy of Management Review, Vol. 24, No.3, pp.522-537.

Daft, R.L. and Sormunen, J. and Parks, D. (1988) Chief executive scanning, environmental characteristics, and company performance: an empirical study, Strategic Management Journal, Vol. 9, No. 2, PP: 123-139.

Draghici, A. and Draghici, G. (2008) Building a Knowledge Share Culture in a Virtual Organization. Case Study for VRL-KCIP NoE, Methods and Tools for Effective Knowledge Life- Cycle- Management, PP: 45-60.

Field, A. (2009) Discovering Statistics Using SPSS, Third Edition, PP: 1-821.

Gallupe, R.B. (2000), Knowledge Management Systems: Surveying the Landscape, Queen's University at Kingston, Queen's Management Research Centre for Knowledge-Based Enterprises,PP:2-26.

Galunic D. C. and Rodan, S. (1998) Resource Recombinations in the Firm. Knowledge Structures and the Potential for Schumpeterian Innovation”, Strategic Management Journal, 19, 1193-201.

Gao, F., and Li, M. and Clarke, S. (2008) Knowledge, management, and knowledge management in business operations, Journal of Knowledge Management, VOL. 12, NO. 2 2008, pp. 3-17.

Gieskes, J. and Hyland, P, W. and Chapman, R. (2002) Continuous product innovation learning behaviours and knowledge management, International Journal of Entrepreneurship and Innovation Management, Vol. 2, No. 6,PP: 485-500.

Grant, R.W. (1996), Toward A Knowledge based theory of the firm, Strategic Management Journal, 17, PP: 109-122(Winter Special Issue).

Ho, D. (2007) Research, Innovation and Knowledge Management: the ICT Factor, PP: 1-11. 
http://jobfunctions.bnet.com/abstract.aspx?docid=1028577 (2009) Driving Cost Efficiency with Business Process Knowledge Management.

Hughes, L. P. and Holbrook, J. A. D. (1998) Measuring Knowledge Management: A New Indicator of Innovation in Enterprises, PPP: 1-16.

Jones, J.W. and Saunders, C. and McLeod, Jr, R. (1993) Media Usage and Velocity in Executive Information Acquisition: An Exploratory Study, European Journal of Information Systems, Vol. 2, No. 4, 260-272.

Katila, R. and Ahuja, G. (2002) Something Old, Something New: A Longitudinal Study of Search Behavior and New Product Introduction, Academy of Management Journal, Vol. 45, PP: 1183-1195.

Kiku, J. (2006) knowledge Management as a Foundation for Decision Support Systems, The Journal of Computer Information Systems.

King, W.R. and Chung, T.R.and Haney, M.H. (2008) Knowledge Management and Organization Learning, the International Journal of Management Science, Omega, Vol. 36, PP: 167-172.

Laudon K. and Laudon J., (, 1996) Management Information Systems Organization and Technology, $4^{\text {th }}$ Edition, Prentice Hall, New Jersey, PP: 600- 611.

Laudon, K. \& Laudon, J. (1994) Management and Information systems: Organisation and technology, 3rd ed. New York: Macmillan.

Lavrac, N. And Mozetic, I. (1989) Methods for Knowledge Acquisition and Refinement in Second Generation Expert Systems, No. 108, PP: 63-69

Lee, S. M. and Chen, J. Q. (1997) A conceptual model for executive support systems, Logistics Information Management, Vol. 10, No. 4, PP: 154-159.

Liao, S. and Wu, C. and Hu, D. and Tsuei, G. (2009) Knowledge Acquisition, Absorptive Capacity, and Innovation Capability: An Empirical Study of Taiwan's Knowledge-Intensive Industries, World Academy of Science, Engineering and Technology, Vol. 53, PP: 160-167.

Liebowitz, J. (1998) Expert systems: An integral part of knowledge management, The International Journal of Cybernetics, Systems and management Sciences, Vol. 27, No.2, pp. $170-175$.

Loren, F. Jaana, W. and John. K. (2003) Knowledge Sourcing: Internal or External? Organizational Learning and Knowledge, $5^{\text {th }}$ International Conference, Canada, PP: 1-17.

Maier, R. and Remus, U. (2003) Implementing Process-oriented Knowledge Management Strategies, Journal of Knowledge Management, Vol. 7, No. 4, PP: 62-74.

March, J. (1991), Exploration and Exploitation in Organizational Learning. Organization Science Vol. 2, No.1, PP: 71-87.

McGrath, R. G. (2001) Exploratory Learning, Innovative Capacity, and Managerial Oversight, 
Academy of Management Journal, Vol. 44, PP: 118-132.

Mood, A. and Franklin, A. and Graybill, D., 1974, Introduction to the Theory of Statistics, Third Edition, 241-246.

OECD, (1996) The knowledge-based economy.

Peters, T. (1993), Leveraging Knowledge, http:// www.tompeyers. Com/ content/ columns/ t leveraging. Html.PP:95-116.

Prahalad, C.K. and Bettis, R.A. (1986) The dominant logic: a new linkage between diversity and performance, Strategic Management Journal, Vol. 7 pp.458-501.

Puranam, P. (2001) The Management and Performance of Technology Grafting Acquisitions, PP: 1-65.

Sasson, J. R. and Douglas, I. (2006) A conceptual integration of performance analysis, knowledge management, and technology: from concept to prototype, Journal of Knowledge management, VOL. 10, NO. 6, pp. 81-99.

Spender, J.-C. (1994), Organization Knowledge Collective Practice and Penrose Rents, International Business Review, VOL. 3, NO.4. pp. 353-367.

Sui, L. (2005) Decision Support Systems Based on Knowledge Management, PP: 1153-1156.

Tsang, W.K., (1997), Organizational Learning and the Learning Organization: A Dichotomy between Descriptive and Prescriptive Research', Human Relations, Vol. 50 No.1, PP: 73-89.

\section{Author Profile}

Corresponding author: Mohammed, A. Ahmed AL-DUJAILI, Assistant Prof., PhD student, Quality Control, Knowledge Systems, School of Mechanical, Aerospace \& Civil Engineering, University of Manchester, M13 9PL, UK,

Mohammed.Al-Dujaili@postgrad.manchester.ac.uk,or mhammedaldujaili@yahoo.co.uk 